\section{THU0119 SUCCESSFUL PSYCHOPHARMACOTHERAPY OF ANXIETY AND DEPRESSIVE DISORDERS IMPROVES RHEUMATOID ARTHRITIS REMISSION RATE AT FIVE YEARS FOLLOW-UP}

Anton Abramkin ${ }^{1}$, Tatiana Lisitsyna ${ }^{1}$, Dmitry Veltishchev² ${ }^{2}$, Olga Seravina², Oksana Kovalevskaya ${ }^{2}$, Svetlana Glukhova ${ }^{1}$, Evgeny Nasonov ${ }^{1} .{ }^{1}$ V.A. Nasonova Research Institute of Rheumatology, Moscow, Russian Federation; ${ }^{2}$ Moscow Research Institute of Psychiatry, "National Medical Research Center of Psychiatry and Narcology» Ministry of Health of Russia, Stress disorders, Moscow, Russian Federation

Background: Anxiety and depressive disorders (ADD) affect rheumatoid arthritis (RA) disease activity and remission rate. Psychopharmacotherapy (PPT) of ADD attempts to improve the remission rate.

Objectives: To determine factors associated with RA remission rate.

Methods: 128 RA-patients (pts) were enrolled, $86 \%$ were women with a mean age of $47,4 \pm 11,3(M \pm S D)$ yrs. All pts met the full ACR criteria for RA. Remission was defined as DAS28<2,6. Mean RA activity by DAS28 was high $(5,27 \pm 1,78)$ at baseline. $69,4 \%$ RA-pts were already taking prednisone $(9[5 ; 10] \mathrm{mg} /$ day $(\mathrm{Me}(25 \% ; 75 \%)), 84,4 \%$ - conventional disease-modifying antirheumatic drugs (cDMARDs), $7,8 \%$ - biologic DMARDs (bDMARDs) - anti-TNF- $\alpha-6,3 \%$, rituximab - 1,6\%. ADD were diagnosed in $123(96,1 \%)$ of RA-pts in accordance with ICD-10 in semi-structured interview. Severity of depression and anxiety was evaluated with Montgomery-Asberg Depression Rating Scale (MADRS) and Hamilton Anxiety Rating Scale (HAM-A). RA-pts with ADD were divided into the following treatment groups: 1 - cDMARDs ( $n=39), 2$ - cDMARDs + PPT (sertraline or mianserine $)(n=43), 3$ - cDMARDs + bDMARDs $(n=32), 4$ cDMARDs + bDMARDs + PPT (sertraline or mianserine) $(n=9)$. Biologics treatment duration varied from 1 to 6 years, antidepressants - from 6 to 96 weeks. Logistic regression analysis was conducted to determine factors associated with RA remission rate.

Results: At 5-yrs endpoint in 83 RA-pts remission rate was $22,9 \%(8,3 \%$, $34,5 \%, 19,0 \%$ and $33,3 \%$ in groups $1,2,3$ and 4 , respectively). Significantly higher proportion of patients achieved remission in CDMARDs + PPT group vs cDMARDs group $(34,5 \%$ vs $8,3 \%$, RR $1,8(95 \% \mathrm{Cl} 0,35-$ $9,2), p=0,024)$. By univariate logistic regression, male sex, younger age, shorter RA duration, RF and ACPA negativity, lower baseline DAS28 and $\mathrm{HAQ}$, absence of extraarticular RA manifestations and depression at the beginning of the study, and remission of anxiety and depressive symptoms at the end of the study were significantly associated with RA remission (table 1). These variables were subjected to multivariate stepwise logistic regression. Only lower baseline DAS28 (OR 0,636 $(95 \% \mathrm{Cl} \quad 0,515$ $-0,785), p<0,001)$ and remission of anxiety and depressive symptoms at 5 -yrs endpoint (OR 6,89 $(95 \% \mathrm{Cl} 1,8-26,29), \mathrm{p}=0,005)$ were independently associated with RA remission at 5 -years follow-up.

Table 1. Factors associated with RA remission at 5 years (univariate logistic regression).

\begin{tabular}{lccccc}
\hline Factor & $p$ & OR & & \multicolumn{2}{c}{$95 \% \mathrm{Cl}$} \\
\cline { 5 - 6 } & & & low & up \\
\hline Female sex & $<0,001$ & 0,310 & 0,166 & 0,577 \\
Baseline age & $<0,001$ & 0,974 & 0,961 & 0,986 \\
RA duration & 0,001 & 0,913 & 0,866 & 0,964 \\
RF + & $<0,001$ & 0,265 & 0,127 & 0,552 \\
ACPA + & 0,003 & 0,321 & 0,152 & 0,681 \\
Baseline DAS28 & $<0,001$ & 0,754 & 0,663 & 0,858 \\
Baseline HAQ & $<0,001$ & 0,381 & 0,236 & 0,614 \\
Baseline extraarticular RA manifestations & 0,005 & 0,211 & 0,072 & 0,619 \\
Baseline minor depression & 0,011 & 0,278 & 0,103 & 0,748 \\
Baseline major depression & 0,028 & 0,353 & 0,139 & 0,895 \\
Baseline generalized anxiety disorder & 0,215 & 0,25 & 0,028 & 2,237 \\
Anxiety and depressive symptoms remission at 5-yrs & 0,007 & 5,891 & 1,63 & 21,29 \\
enpoint & & & & \\
Schizotypal personality disorder & 0,22 & 0,429 & 0,111 & 1,657 \\
\hline
\end{tabular}

Conclusion: Lower baseline DAS28 and remission of anxiety and depressive symptoms at 5-yrs endpoint are associated with higher rheumatoid arthritis remission rate at five years follow-up.

Disclosure of Interests: None declared

DOI: 10.1136/annrheumdis-2019-eular.3553

\section{THU0120 \\ RHEUMATIC DISEASE COMORBIDITY INDEX IMPACT ON DISEASE ACTIVITY IN PATIENTS ENROLLED IN KUWAIT REGISTRY OF RHEUMATIC DISEASES (KRRD)}

YASER Ali ${ }^{1,1}$, Khulood Saleh ${ }^{2}$, Ahmed Enizi $^{3}$, Fatemah Abutiban ${ }^{3}$, Adel Al-

Awadhi ${ }^{4}$, Waleed Al-Kandari ${ }^{2}$, Eman Hasan ${ }^{4}$, Hebah Alhajeri ${ }^{1}$,

Mohammed Hussain ${ }^{4}$, Ahmed Alsaber ${ }^{5}$, Sawsan Hayat ${ }^{1}$, Ali Aledei ${ }^{4}$

Adeeba Herz ${ }^{4}$, Aqeel Ghanem ${ }^{1} .{ }^{1}$ Mubarak Al Kabeer Hospital, Rheumatology,

kuwait city, Kuwait, ${ }^{2}$ Farwania Hospital, kuwait city, Kuwait, ${ }^{3}$ Al Jahrs Hospital,

kuwait city, Kuwait; ${ }^{4}$ Amiri Hospital, kuwait city, Kuwait, ${ }^{5}$ Kuwait Technical college,

Department of Mathematics, kuwait city, Kuwait

Background: Its known that the presence of certain comorbidities in patients with Rheumatoid arthritis (RA) can have an impact on the chance of achieving low disease activity (LDA).

Objectives: The purpose of this study was to examine the association of different comorbidities with low disease activity index in patients enrolled in KRRD.

Methods: The database of KRRD was used to include patients with RA and multiple visits. Comorbid conditions were collected at enrollment by the treating rheumatologist and modeled using the Rheumatic Disease Comorbidity index $(\mathrm{RDCl})$ score, and by individual comorbid condition. Disease activity (DAS28) was assessed at routine clinic visits. Associations of comorbidity measures with disease activity over 4 years of follow up were examined using multivariable linear models. The odds of ever achieving DAS28 low disease activity $(<3.2)$ were examined using multivariable logistic regression.

Results: Among 1511 participants with mean age of 52 (SD 12) years, RA duration 8 (SD 6) years, $60.7 \%$ female, $77.1 \%$ RF positive, $64.6 \%$ anti-CCP positive, and $10.8 \%$ with smoking history, 1.29 had a RDCl. Hypertension $(21 \%)$, diabetes mellitus $(21 \%)$, hyperlipidemia $(12 \%)$, cardiovascular (CV) disease (3.6\%) and interstitial lung disease (ILD) (1.1\%) were the most prevalent comorbidities. Select individual comorbidities, including DM, kidney disease and COPD, were more closely associated with unfavorable longitudinal disease activity, and achievement of low dis ease activity status. Correlation test between DAS28 and all comorbidities showed signification negative association for achieving low disease activity if the patient has history of diabetes mellitus, COPD or kidney disease. Conclusion: DM, kidney disease and COPD but not composite comorbidity scores, are associated with higher measures of disease activity and lower odds of achieving low disease activity status in RA patients enrolled in KRRD registry.

Table (1) : Cox Proportional Hazards Regression for LDA and comorbidities

\begin{tabular}{lccccc}
\hline Variable & $\mathrm{B}$ & $\mathrm{SE}$ & $95 \% \mathrm{Cl}$ & $\mathrm{P}$ & OR \\
\hline DM & 0.24 & 0.05 & $(0.14,0.34)$ & $\mathbf{0 . 0 0 1}$ & $\mathbf{1 . 2 7}$ \\
CAD & 0.16 & 0.13 & $(-0.09,0.40)$ & 0.221 & 1.17 \\
Hyperlipidemia & -0.12 & 0.06 & $(-0.24,0.01)$ & 0.65 & 0.89 \\
Hypertension & -0.04 & 0.05 & $(-0.14,0.05)$ & 0.394 & 0.96 \\
COPD & 0.66 & 0.33 & $(0.01,1.32)$ & $\mathbf{0 . 0 4 7}$ & $\mathbf{1 . 9 4}$ \\
Cancer & 0.86 & 0.45 & $(-0.02,1.74)$ & 0.055 & 2.36 \\
Kidney disease & 0.97 & 0.39 & $(0.20,1.74)$ & $\mathbf{0 . 0 1 4}$ & $\mathbf{2 . 6 3}$ \\
ILD & 0.09 & 0.21 & $(-0.33,0.50)$ & 0.685 & 1.09
\end{tabular}

Disclosure of Interests: None declared

DOI: 10.1136/annrheumdis-2019-eular.445

\section{THU0121 CIRCULATING FIBROBLAST GROWTH FACTOR-23 IS ASSOCIATED WITH DYSLIPIDEMIA IN RHEUMATOID ARTHRITIS PATIENTS}

Antonio Alvarez de Cienfuegos ${ }^{1}$, Lucia Cantero-Nieto ${ }^{2}$, José Alberto GarcíaGómez ${ }^{3}$, Gema Robledo ${ }^{4}$, Marta Trigo ${ }^{5}$, Javier Martin lbanez ${ }^{4}$, Miguel A GonzálezGay $^{6}$, Norberto Ortego ${ }^{7}{ }^{1}$ Vega Baja Hospital, Rheumatology, Orihuela, Spain; ${ }^{2}$ Santa Ana Hospital, Emergency, Granada, Spain; ${ }^{3}$ Hospital General Universitari $d^{\prime} E I x$, Elche, Spain; ${ }^{4}$ Institute of Parasitology and Biomedicine López-Neyra, IPBLN-CSIC, Granada, Spain; ${ }^{5}$ Hospital San Cecilio, Internal Medicine, Granada, Spain; ${ }^{6}$ IDIVAL, Santander, Spain; ${ }^{7}$ Hospital Universitario San Cecilio, Internal Medicine, Granada, Spain

Background: Rheumatoid arthritis (RA) patients have an increased risk of morbidity and mortality from cardiovascular (CV) events as a result of accelerated atherosclerosis. The bone-derived fibroblast growth factor-23 (FGF23) is a novel marker of chronic kidney disease (CKD)-associated mineral bone disorder, which increases progressively with declining renal function. FGF23 is associated with left ventricular hypertrophy, impaired left ventricular function, endothelial dysfunction, heart failure and progression of renal failure in adult CKD. 
Objectives: The objectives of this study were to: compare serum FGF-23 levels between $R A$ patients and healthy controls and investigate possible associations between FGF23 as surrogate measures of cardiovascular disease.

Methods: This cross-sectional study was performed in Vega-Baja Hospital, Orihuela (Spain) from November 2016 to May 2018. We prospectively enrolled 63 consecutive women patients affected by RA and followed at the Vega-Baja Hospital (Orihuela, Spain) and 65 matched healthy women controls. All patients included in this study had normal serum creatinine (Cr) levels and met the 2010 American College of Rheumatology/European League Against Rheumatism (ACR/EULAR) criteria for RA. Total cholesterol and triglyceride levels were determined by fully enzymatic techniques. High-density lipoprotein (HDL) was determined after precipita-

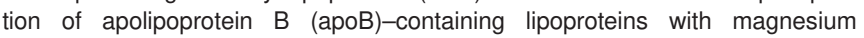
sulfate and dextran sulfate. Low-density lipoprotein (LDL) was calculated using the Friedewald formula. Serum FGF-23 was analyzed using ELISA. Results: The mean serum total cholesterol, HDL-C, LDL-C, and triglycerides were $212.74 \pm 41 \mathrm{mg} / \mathrm{dL}, 69.92 \pm 19.45 \mathrm{mg} / \mathrm{dL}, \quad 120.18 \pm 29.24 \mathrm{mg} / \mathrm{dL}$ and $112.93 \pm 55.67 \mathrm{mg} / \mathrm{dL}$, respectively.

There was no significant differences in FGF-23 levels between the patients and controls $[85.7(5.2-275.4)$ vs. $81.2 \quad(2.6-269.9), \quad \mathrm{pg} / \mathrm{ml}$; $P=0.4316]$, but we found that FGF23 levels were positively associated with total cholesterol $(p<0.05)$, low-density lipoprotein (LDL-c) level ( $p$ $<0.05)$ and smoking $(p=0.008)$ in patients with RA.

Conclusion: We report an association between circulating FGF-23 and LDL-C in RA patients, representing a novel pathway linking high FGF23 to an increased cardiovascular risk.

\section{REFERENCES}

[1] Castañeda S, Nurmohamed MT, González-Gay MA. Cardiovascular disease in inflammatory rheumatic diseases. Best Pract Res Clin Rheumatol. 2016; 30(5):851-869.

[2] Kendrick J, Cheung AK, Kaufman JS, Greene T, Roberts WL, Smits G, Chonchol M. FGF-23 associates with death, cardiovascular events, and initiation of chronic dialysis. J Am Soc Nephrol. 2011; 22(10):1913-1922.

[3] Scialla JJ, Xie H, Rahman M, Anderson AH, Isakova T, Ojo A, et al. Fibroblast growth factor-23 and cardiovascular events in CKD. J Am Soc Nephrol. 2014; 25(2):349-360.

[4] Mirza M, Alsiö J, Hammarstedt A, Erben RG, Michaëlsson K, A Tivesten $\AA$, et al. Circulating Fibroblast Growth Factor-23 Is Associated With Fat Mass and Dyslipidemia in Two Independent Cohorts of Elderly Individuals. Arterioscler Thromb Vasc Biol. 2011; 31:219-227.

Disclosure of Interests: Antonio Alvarez de Cienfuegos : None declared, Lucia Cantero-Nieto: None declared, José Alberto García-Gómez: None declared, Gema Robledo: None declared, Marta Trigo: None declared, Javier Martin Ibanez: None declared, Miguel A González-Gay Grant/ research support from: Prof. MA Gonzalez-Gay received grants/research supports from Abbvie, MSD, Jansen and Roche., Speakers bureau: Consultation fees/participation in company sponsored speaker's bureau from Pfizer, Lilly, Sobi, Celgene, Novartis, Roche and Sanofi., Norberto Ortego: None declared

DOI: 10.1136/annrheumdis-2019-eular.5076

\section{THU0122 THE LACK OF EXERCISE HABIT WAS A RISK FACTOR FOR CLINICAL FRACTURES IN PATIENTS WITH RHEUMATOID ARTHRITIS -TOMORROW STUDY-}

Shohei Anno ${ }^{1,2}$, Kentaro Inui $^{3}$, Yuko Sugioka ${ }^{4}$, Kenji Mamoto $^{3}$, Tadashi Okano ${ }^{2}$, Masahiro Tada ${ }^{5}$, Tatsuya Koike ${ }^{6,7}$, Hiroaki Nakamura ${ }^{2}{ }^{1}{ }^{\text {Osaka social medical }}$ center, Orthopaedic Surgery, Osaka, Japan; ${ }^{2}$ Osaka City University Graduate School of Medicine, Orthopaedic Surgery, Osaka, Japan; ${ }^{3}$ Osaka City University Graduate School of Medicine, Orthopaedic Surgery, Osaka, Japan; ${ }^{4}$ Osaka City University Graduate School of Medicine, Center for Senile Degenerative Disorders (CSDD), Osaka, Japan; ${ }^{5}$ Osaka City General Hospital, Orthopaedic Surgery, Osaka, Japan; ${ }^{6}$ Osaka City University Graduate School of Medicine, Center for Senile Degenerative Disorders (CSDD), Osaka, Japan; ${ }^{7}$ Search Institute for Bone and Arthritis Disease (SINBAD), Osaka, Japan

Background: Patients with rheumatoid arthritis (RA) might be considered to be at increased risk of falls and fractures. However, little is known about the exact properties of risk factors for clinical fractures in patients with RA. Recently, the disease activity of RA has been more satisfactorily controlled by the "treat-to-target" strategy, including the use of biologics. Given this new era, it is important to accurately estimate the incidence of clinical fracture in patients with RA and to elucidate contributing risk factors.
Objectives: The objective of this study was to evaluate the incidence of clinical fractures and associated risk factors in 208 patients with RA and in age- and sex-matched 205 controls (Cont) who participated in the

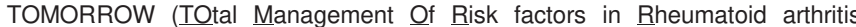
patients to IOW er morbidity and mortality) study, a 10-year cohort study that started in 2010 in Japan. This research was conducted using TOMORROW study data for 7 years.

Methods: We evaluated the incidence of clinical fractures by self-administered questionnaire every year and confirmed them by medical records. We also collected information about daily walking time and weekly exercise time, general health status, body composition including bone mineral density, lean body mass, fat mass and laboratory data at baseline. We compared the frequency of the incidence of clinical fractures in RA patients and Cont for seven years and analyzed risk factors for clinical fractures in RA patients using multivariate regression analysis.

Results: A total of 208 patients with RA (mean age: $54.9 \pm 10.1$ years, female: $85.1 \%$, mean disease duration $14.0 \pm 11.8$ years) and 205 Cont (mean age: $56.3 \pm 10.4$ years, female: $83.9 \%$ ) were finally analyzed. The number of clinical fractures were no differences between RA and Cont group (RA: 47, Cont: 38, $\mathrm{p}=0.37$ ). Comparing RA patients with or without the clinical fractures, age $(p=0.006)$, disease duration $(p=0.005)$, the average glucocorticoid dose $(p<0.001)$, the average number of falls $(p<0.001)$, and the average DAS28-ESR of seven years $(p=0.029)$ were higher in patients with the incidence of clinical fractures. Multivariate logistic regression analysis revealed that RA was not a risk factor (OR: $0.655,95 \% \mathrm{Cl}$ : $0.296-1.448, p=0.296$ ), and the lack of exercise habit (OR: $2.221,95 \%$ $\mathrm{Cl}$ : 1.208-4.082, $\mathrm{p}=0.001$ ) and glucocorticoid use (OR: $2.279,95 \% \mathrm{Cl}$ 1.036-5.015, $p=0.04$ ) were the risk factor for clinical fractures. Multivariate logistic regression analysis in RA patients, the lack of exercise habit represented an independent risk factor for the incidence of clinical fractures (OR: 4.466, 95\% Cl: 1.212-16.454, $\mathrm{p}=0.025$ ).

Conclusion: Seven years of data from the TOMORROW cohort study including both RA patients and age- and sex-matched Cont showed no difference in the incidence rate of clinical fractures between RA and Cont groups. Multivariate logistic regression analysis revealed that RA was not a risk factor. However, the lack of exercise habit was significantly associated with an increased frequency of the incidence of clinical fracture among RA patients.

Acknowledgement: We wish to thank Atsuko Kamiyama, Tomoko Nakat suka and the members of the Osaka City University hospital clinical research center.

Disclosure of Interests: Shohei Anno: None declared, Kentaro Inui Speakers bureau: Takeda Pharmaceutical, Pfizer Japan, Daiichi-Sankyo Co.Ltd. Abbvie, Mitsubishi Tanabe Pharma Corporation, Janssen Pharmaceutical, Chugai Pharmaceutical, Ono Pharmaceutical, Eisai Co.Ltd., Eli-Lilly, Nippon Kayaku Co.,Ltd., Maruho Co.,Ltd, Kaken Pharmaceutical Co.,Ltd. Yuko Sugioka: None declared, Kenji Mamoto: None declared, Tadashi Okano Speakers bureau: AbbVie, Masahiro Tada Speakers bureau: Abbvie, Astellas Pharma, Bristol-Myers Squibb, Chugai Pharmaceutical, Eisai, Janssen Pharmaceutical, Mitsubishi Tanabe Pharma Corporation, Ono Pharmaceutical, Pfizer Japan, Takeda Pharmaceutical

Tatsuya Koike Speakers bureau: AbbVie, Astellas Pharma Inc., BristolMyers Squibb, Chugai Pharmaceutical, Eisai, Janssen, Lilly, Mitsubish Tanabe Pharma Corporation, MSD, Ono Pharmaceutical, Pfizer, Roche, Takeda Pharmaceutical, Teijin Pharma, and UCB, Hiroaki Nakamura: None declared

DOI: 10.1136/annrheumdis-2019-eular.3427

\section{THU0123 \\ FEMALES UNDERGO MORE TREATMENT CHANGES COMPARED TO MALES: ANALYSIS OF GENDER DIFFERENCES IN RHEUMATOID ARTHRITIS PATIENTS}

ASTORRI DAVIDE ${ }^{1}$, Francesca Ometto ${ }^{2}$, Lara Friso $^{3}$, Francesco Sartor ${ }^{3}$, Bernd Raffeiner ${ }^{4}$, Costantino Botsios ${ }^{5}$, Leonardo Punzi ${ }^{6}$, Andrea Doria ${ }^{3}$. ${ }^{1}$ UNIVERSITY OF PADOVA, RHEUMATOLOGY UNIT,DEPARTMENT OF MEDICINE (DIMED), PADOVA, Italy; ${ }^{2}$ UNIVERSITY OF PADOVA, RHEUMATOLOGY UNIT, DEPARTMENT OF MEDICINE (DIMED), PADOVA, Italy, ${ }^{1}$ UNIVERSITY OF PADOVA, RHEUMATOLOGY UNIT,DEPARTMENT OF MEDICINE (DIMED), PADOVA, Italy; ${ }^{2}$ UNIVERSITY OF PADOVA, RHEUMATOLOGY UNIT, DEPARTMENT OF MEDICINE (DIMED), PADOVA, Italy; ${ }^{1}$ UNIVERSITY OF PADOVA, RHEUMATOLOGY UNIT,DEPARTMENT OF MEDICINE (DIMED), PADOVA, Italy; ${ }^{1}$ UNIVERSITY OF PADOVA, RHEUMATOLOGY UNIT,DEPARTMENT OF MEDICINE (DIMED), PADOVA, Italy

Background: Gender differences may contribute to treatment tailoring in rheumatoid arthritis (RA) patients. Observational data shows a trend toward worse disease activity and worse response to treatment in 